Development of a Real-Time Radiological Area Monitoring Network for Emergency Response at Lawrence Livermore National Laboratory

N. A. Bertoldo, S. L. Hunter, R. A. Fertig,

G. W. Laguna, D. H. MacQueen

April 5, 2004

IEEE Sensors Journal 
This document was prepared as an account of work sponsored by an agency of the United States Government. Neither the United States Government nor the University of California nor any of their employees, makes any warranty, express or implied, or assumes any legal liability or responsibility for the accuracy, completeness, or usefulness of any information, apparatus, product, or process disclosed, or represents that its use would not infringe privately owned rights. Reference herein to any specific commercial product, process, or service by trade name, trademark, manufacturer, or otherwise, does not necessarily constitute or imply its endorsement, recommendation, or favoring by the United States Government or the University of California. The views and opinions of authors expressed herein do not necessarily state or reflect those of the United States Government or the University of California, and shall not be used for advertising or product endorsement purposes. 


\title{
Development of a Real-Time Radiological Area Monitoring Network for Emergency Response at Lawrence Livermore National Laboratory
}

\author{
Nicholas A. Bertoldo, Steven L. Hunter Senior Member, IEEE, Ronald A. Fertig, Gary W. Laguna, \\ and Donald H. MacQueen
}

\begin{abstract}
A real-time radiological sensor network for emergency response was developed and deployed at the Lawrence Livermore National Laboratory (LLNL). The RealTime Radiological Area Monitoring (RTRAM) network is comprised of 16 Geiger-Mueller (GM) sensors positioned on the LLNL Livermore site perimeter to continuously monitor for a radiological condition resulting from a terrorist threat to site security and the health and safety of LLNL personnel. The RTRAM network sensor locations coincide with wind sector directions to provide thorough coverage of the one square mile site. These low-power sensors are supported by a central command center (CCC) and transmit measurement data back to the CCC computer through the LLNL telecommunications infrastructure. Alarm conditions are identified by comparing current data to predetermined threshold parameters and are validated by comparison with plausible dispersion modeling scenarios and prevailing meteorological conditions. Emergency response personnel are notified of alarm conditions by automatic radio and computer based notifications. A secure intranet provides emergency response personnel with current condition assessment data that enable them to direct field response efforts remotely. The RTRAM network has proven to be a reliable system since initial deployment in August 2001 and maintains stability during inclement weather conditions.
\end{abstract}

Index Terms-Radiation dispersion modeling, emergency response alarm notifications, real-time radiation monitoring, sensor networks.

\section{INTRODUCTION}

A PASSIVE real-time radiation area monitoring network (RTRAM) was installed at Lawrence Livermore National Laboratory (LLNL) using commercially available technology enhanced to meet LLNL design criteria. This network of radiological sensors provides data on ionizing radiation from 16 remote area sensors to a Central Command Center (CCC) computer in real-time. The CCC computer manages and routes the data to other computer systems for further processing. By incorporating alarm functions into the computer's data acquisition software, Emergency Operations Center (EOC), personnel are immediately notified of any radiological incident within the sensor's proximity that exceeds conditional alarm thresholds at that instant. The EOC may then direct

Manuscript received March, 31, 2004. This work was performed under the auspices of the U.S. Department of Energy by the University of California, Lawrence Livermore National Laboratory under contract No. W-7405-Eng48. UCRL-JRNL-203376 action accordingly on the basis of current information.

\section{A. Site Background}

The LLNL Livermore site is approximately one mile square and may be characterized as an industrial setting for dispersion modeling purposes. Suburban housing, rural land, and other industrial complexes surround the site. This former World War II era Naval Air Station was converted to a research laboratory in 1952. LLNL continues to use some of these older facilities, which presented RTRAM component installation challenges, (i.e., communication infrastructure in the older facilities and perimeter location).

\section{B. Challenges of Real-Time Monitoring}

Monitoring for airborne radioactivity produced by a dirty bomb is a challenging activity. Selection of the proper monitoring equipment depends on the radioactive material's physical state, (i.e., gaseous or particulate) [1]. Collection methodologies may be either passive or active and provide either a quantitative or qualitative result. Two examples of passive quantitative sensors are thermoluminescent dosimeters and pressurized ion chambers which are used to measure radiation dose.

Active sampling devices such as air samplers, have filters made from specific material that enhance the collection of either gaseous or particulate samples. Examples of gaseous collection media are carbon filters for the collection of radioiodine and silica gel for the collection of Tritium. These devices are also quantitative measurement sensors. Analogous to the volume of air breathed, an air sample measured for air activity per unit volume sampled represents the integrated air concentration for the sampling period. Active air sampling of this type is beneficial in exposure determinations.

Air particulate mass loading of the filter media usually occurs over a 1 week period after which the filter is removed from the field for analysis. This media is useless for gaseous radioactive material producing gamma radiation directly or by neutron induced secondary reactions. This is one example where the radiation type or physical state determines the sensor technology used to collect a sample for either quantitative or qualitative determination. Standard laboratory radioanalytical techniques are used to determine the type and quantity of radioactive material collected by filter media and several different analysis techniques may be required to gather 
all of the desired information. The process may be quite lengthy from placement of the collection media until receipt of the analytical results.

Further challenges based on radiation sensor types, (i.e., active or passive) and real-time data analysis are presented not only by power restrictions for field sensors but also by communication restrictions. LLNL maintains strict security requirements due to its national security mission.

Real-time identification of non-background radiation is a challenge in many respects. For example, in order to obtain isotopic identification in real-time, the monitoring equipment must be much more complicated which imposes further network design constraints. Additionally, other factors that impose requirements on real-time sensor designs are radiation type, elemental physical state, and physical decay half-lives.

\section{SENSOR TECHNOLOGY}

\section{A. Technology}

The LLNL design goal was to detect all radiation types, be robust under environmental conditions, and be economical to operate. Priority was given to a network design utilizing components from commercial available technology. Gas filled ionization counter technology provides a means of detection for all radiation types, in any elemental physical state (i.e., gaseous, liquid, or particulate). Geiger-Mueller (GM) counters, which were introduced in 1928 [2], are still considered the simplest radiation sensor to operate. GM counters provide the necessary detection properties for this application and have the benefit of reliability and sensitivity in low-radiation fields encountered in the environment following dispersion of low activity sources. Inherent difficulties exist in detecting alpha radiation produced by transuranic radioactive decay. The presence of natural occurring decay products [3] can mask regions of interest for the detection of low-level radiations from Plutonium-239 and Americium-241. However, by monitoring the ambient background environment continuously in real-time using GM counters, elevated count rates from any source are easily measured. The benefits of a qualitative response with this sensor technology override its limitations (that do not exist in other advanced devices). A thorough treatment of available technology may be found in [2].

\section{RTRAM SENSORS}

\section{A. Sensor}

The sensors deployed are pancake tube designs by LND Inc. that are mounted to the circuit board designs of AWARE Electronics Inc. The AWARE sensor circuit contains the components necessary to supply an applied voltage $\left(\mathrm{V}_{\mathrm{a}}\right)$ to power the sensor and provide an output signal voltage $\left(\mathrm{V}_{\mathrm{s}}\right)$ maintained at positive voltage potential for the CCC.

The mass thickness of the sensor's mica thin window is 1.5 to $2.0 \mathrm{mg} / \mathrm{cm}^{2}$ to allow charged particles, e.g., alpha $(\alpha)$ and beta $(\beta)$, to enter the gas volume and begin an ionization event. The upper range of the mass thickness tolerance at 2.0 $\mathrm{mg} / \mathrm{cm}^{2}$ will allow the penetration of $\alpha$-particles greater than 3 $\mathrm{MeV}$ [4]. Alpha particles with energies ranging from 4 to 5 Mev will penetrate a mean range of 2.5 to $3.5 \mathrm{~cm}$ in air at standard temperature and pressure respectively. A mica thin window mean mass thickness range of 1.5 to $2.0 \mathrm{mg} / \mathrm{cm}^{2}$ is easily penetrated for the suite of transuranic isotopes that might be used in the composition of a radiological dispersal device ("dirty bomb").

\section{B. Charge Recovery}

Each ionization event that occurs in the sensitive gas volume creates electrons and cations. The heavier cations migrate to the chamber wall at a much slower rate than the self-propagation of electron avalanches (i.e., Townsend), which are collected by the anode. The Geiger discharge results in a build-up of cations that surround the anode wire of the sensor and prevent further charge collection [5]. A halogen quench gas is used to accelerate the sensor recovery with about $100 \mu$ s dead time adequate for low-level counting.

The alpha radiation calibration factor for the RTRAM sensor is $150 \mathrm{cpm} / \mathrm{nCi}(1 \mathrm{nCi}=1.0 \mathrm{E}-09 \mathrm{Ci}) \mathrm{Pu}-239$. Although a significantly high counting rate will saturate the sensors, the rate loss percentage is insignificant by comparison to the air concentration required to produce such a condition over the coverage area of 1 sq. mile. Once this sentry system has reached an alarm condition, health and safety mitigation steps such as "shelter in place" automated warnings will take precedence over continued measurement.

\section{NETWORK POWER AND SIGNAL DISTRIBUTION}

\section{A. Power and Signal Circuitry Overview}

Each of the 16 remote sites is connected independently to the CCC by circuits consisting of two unshielded twisted pairs of copper wire provided by the LLNL site infrastructure. The positive and negative applied voltage, signal, and reference ground are maintained by the CCC circuit for each remote sensor. The CCC circuitry maintains $\mathrm{V}_{\mathrm{a}}$ at \pm 15 volts direct current $(\mathrm{vdc})$ on one pair while the signal and reference ground are maintained via the other pair. The signal pin of the sensor is held at $+4.7 \mathrm{vdc}$ until ionization occurs in the gas volume. Once ionization occurs in the gas, $\mathrm{V}_{\mathrm{s}}$ drops below zero. Each occurrence of this drop in potential indicates an ionization event. Two National Instruments (NI) PCI-6602 circuit boards were installed in the CCC computer to interface with the LabVIEW ${ }^{\mathrm{TM}}$ data acquisition program and count the ionization events. Since the LLNL communication infrastructure is well established site-wide, sensors may be located at any facility on the site. This allows the flexibility to relocate or add sensors to the network.

\section{CENTRAL COMMAND CENTER}

\section{A. PC Computer and Sensor Network Power}

The RTRAM CCC computer uses the Windows ${ }^{\circledR} 2000$ operating system. To ensure continuous operation during a power outage, emergency power is provided by backup diesel generator. The low-power consumption of the computer and 
the sensor network permits up to 30 minutes of operation by uninterruptible power supply should the backup generator fail to start.

\section{B. Hardware Design}

The output of the RTRAM sensor facilitates connection over long transmission lines. Even though some of these lines are over $3 \mathrm{~km}$ long (due to indirect circuit pathways) the low power consumption of the sensor minimizes the voltage drop. The sensor has an open collector output that pulls the output to the negative supply when ionization in the sensitive volume occurs. There is a weak pull-up resistor to restore the output to the positive rail. With the output signal swinging between both rails, there is a lot of noise margin for long transmission lines.

The output signals of all of the sensors run through interface circuits to the NI PCI-6602 multichannel counter board installed in the CCC computer. The interface circuit is a $4.7 \mathrm{~V}$ zener diode to ground and a $1 \mathrm{~K}$ ohm resistor to +15 volts. The diode clamps the positive signal to $+4.7 \mathrm{~V}$ and clamps the negative pulses to approximately -0.7 volts. The $1 \mathrm{~K} \mathrm{ohm}$ resistor speeds up the pulse rise time so that closely spaced pulses are detected better and reduces the effects of noise on the slowly rising signal. The counter board that we used has Schmitt-trigger inputs to avoid retriggering the counter as the detector pulse rises.

During the prototype phase of the project we used a counter board that did not have Schmitt-trigger inputs, and we had to use an external Schmitt-trigger input buffer to avoid getting multiple counts due to the noise on the rising edge of the detector pulse. Testing with a digitizing oscilloscope showed that the combination of the above interface and the Schmitttrigger inputs produces good noise immunity and a single count for each detection pulse.

\section{CONTROL PANEL}

\section{A. LabVIEW ${ }^{\mathrm{TM}}$ Data Acquisition Software}

A LabVIEW ${ }^{\mathrm{TM}}$ program is used to monitor the RTRAM sensor signal input, process and save the data locally, and send it to a UNIX file server. The LabVIEWTM program's Data Acquisition State Machine idles until the interval timer trips and then goes through the following states:

$$
\begin{array}{ll}
\text { - } & \text { Get Data } \\
\text { - } & \text { Calculate } \\
\text { - } & \text { Dism Check } \\
\text { - } & \text { Log Data }
\end{array}
$$

\section{B. Alarm Monitor}

The Alarm Indicator Management Loop runs continuously, scanning the "Alarm Global" variable which contains the parameter information for the alarm conditions. The "Alarm Global" variable contains the alarm parameter information for each of the channels being monitored by the system. The system allows alarm categories to be set for different responder action on the basis of alarm level. Upon detection of an alarm condition for any channel, the Alarm Contact Notification function is activated and sends out alpha pages for each channel that is alarming to all the selected officials associated with each alarm category. LabVIEW ${ }^{\mathrm{TM}}$ also sends electronic mail notification following the paging notice. Notices include alarm level, count rate, and the time to reach the threshold parameter dose at the present count rate.

The Alarm Indicator also activates an audio alarm on the CCC computer while the background color of the chart display for the alarming sensor is changed from a black to yellow background. The numerical value representing the number of hours that is required to reach a threshold dose at the present rate is boldly written in red text in the center of the display over the yellow background.

\section{Setup Panel}

The setup panel is the user interface for setting all program parameters and is accessed through a function on the system user control panel. For security purposes this panel has password protection in order to maintain system integrity. The setup panel allows the alarm test function to be initiated and operate independently of the normal operation. Details of the Alarm Test function are discussed below.

\section{ALARM ALGORITHM AND TEST FUNCTION}

\section{A. Alarm Algorithm}

The alarm function is used for notification that action levels have been reached. It is triggered by the RTRAM CCC and by computer program that produces the "Action Level Status" display.

Action levels are specified in terms of the number of hours (denoted by $T_{S}$ ) to reach a point source dose threshold limit $\left(D_{L}\right.$, millirem). This threshold is based on a sensor calibration using Cs-137 gamma reference energy of 662 kilo electron Volts $(\mathrm{keV})$. Alarm response is determined for each sensor $(S)$, based on whether the present count rate in counts/minute $(\mathrm{cpm})$ of a short test period $\left(\bar{x}_{\text {test }}, \mathrm{cpm}\right)$ exceeds a reference or background value $(B, \mathrm{cpm}) . T_{S}$ is calculated by

$$
T_{S}=\frac{k D_{L}}{D_{c f}\left(\bar{x}_{\text {test }}-B\right)}
$$

where $k$ and $D_{c f}$ are unit conversion factors;

$$
\begin{gathered}
k=1000 \frac{\mu \mathrm{R}}{\text { millirem }} \text {, and } \\
D_{c f}=0.187 \frac{\mu \mathrm{R} / \mathrm{hr}}{\mathrm{cpm}}
\end{gathered}
$$

In normal operation at LLNL, $\bar{x}_{\text {test }}$ is the average of the most recent three measurements, and $B$ is either the average of the previous 30 measurements, or a fixed value of $30 \mathrm{cpm}$, whichever is smaller.

The averaging of a small test set filters out randomly occurring transient (single measurement) spikes that could trigger a false alarm. The nature of dispersion eliminates the likelihood of singularities and is dependent on meteorological conditions and the duration of a plume passage event. 
$T_{S}$ is recalculated every time a new measurement is acquired, separately for each sensor.

Specifying action levels in terms of hours until a dose threshold is reached provides first responders with a gauge of the level of urgency from which to manage the incident as conditions change.

\section{B. Alarm Test Function}

The alarm test function provides a wellness check to ensure operational readiness. RTRAM network administrators perform periodic tests of the alarm notification process by selection of the "Alarm Test Function" located on the password secured set-up panel. As the alarm test program loads, a sensor selection menu that contains independent alarm level selector settings is displayed. The administrator may then select any number of network sensors and the test level to be conducted. The test results of actual pseudo-alarm condition values is sent through the radio paging and email text messaging system. An example of the message is shown below:

From: RTRAM@1lnl.gov

Subject: Rad Action Level 4

Sensor-15*Alarm_Test* | 22Hrs. -> 2 mrem | 499cpm 08:41 01/27/04

The message contains the following data:

- Action Level

- Sensor Identification

- *Alarm_Test* (blank if real condition exists)

- Number of hours to reach the threshold dose

- The threshold dose (2 millirem)

- The count rate (counts / minute)

- The time and date stamp

\section{DATA COMMUNICATION FOR THE SECURE INTRANET}

\section{A. Socket Communications}

The RTRAM system uses sockets to communicate between the CCC computer and the UNIX file server. The listener process on the UNIX file server opens sockets for reading, while the CCC computer attaches to those sockets for writing. The CCC computer opens a new socket connection each time it has data to be sent. This improves reliability over a persistent connection, because this decouples the operations of the CCC computer and the listener. If the CCC computer is unable to open a socket (e.g. network problems, power outages, etc.), the data is buffered by LabVIEW ${ }^{\text {TM}}$, dynamically allocating space as needed, and sent along with current data the next time the CCC computer is able to make a connection. Scheduled UNIX file server down-time, has shown no loss of data for periods of up to 3 days $(69,120$ data records at the 1 per minute rate of data acquisition for 16 locations). LabVIEW ${ }^{\text {TM }}$ maintains local copies of the data as an insurance policy in the event of a catastrophic failure of the UNIX file server resulting in significant down-time.

\section{B. Data Packets}

Each data packet is transmitted in ASCII format, and contains the location identifier, a time stamp, and the sensor readings. Data is currently stored to flat files on the UNIX file system for rapid access to current data, and to a MySQL $\mathrm{B}_{\circledast}$ database which provides greater flexibility for reporting and data management.

\section{Listener Health \& System Reliability}

The RTRAM Listener resides on the UNIX file server and receives files from the $\mathrm{CCC}$ computer. This script is configured to be started any time the UNIX host is restarted. This ensures that if the host goes down, whether intentionally or not, the listener will be available as soon as the host is able to support it. Additionally, a listener health program runs hourly to ensure that the listener is still active. If the listener is not active, the program attempts to restart the listener, and an email is sent to system administrators indicating whether or not the listener was successfully started. Should these measures fail, yet another monitoring process is run from a separate host which will notify administrators when either RTRAM or the UNIX file server is unavailable.

\section{Monitoring of Conditions}

In addition to the alarm sequences mentioned above, the UNIX file server also provides alarms to users and system administrators. A system operational check is done by the listener to ensure data is being received. If no data is received by the CCC computer, LabVIEW ${ }^{\mathrm{TM}}$ sends a zero in the string for that sensor and the listener responds by sending a page to network administrators identifying the down sensor.

\section{THE SECURE INTRANET SITE}

\section{A. Overview}

The RTRAM is a secure intranet site and serves as the primary interface for system users, emergency response personnel, and network administrators. The RTRAM computer displays provide both real-time and historical data for consequence analysis and modeling.

Dispersion modeling relies on source term information and other meteorological parameters to drive the modeling functions and produce an estimate of the exposure, deposition, and the extent of a radiological emergency. Sensor driven modeling is now being added as a resource for use in dispersion modeling codes.

\section{B. Intranet Interface}

An aerial view perspective line drawing of the LLNL site is shown in Figure 1. A graphical display is used to visualize the position of the sensor system, provide hotlinks to sensor data pages, and correlate any plotted dispersion information. Each sensor location depicted on the site map is linked to specific information for that sensor. Presently this includes a close-up map, current sensor status and readings, current wind conditions, as well as links to available plots for that sensor. 


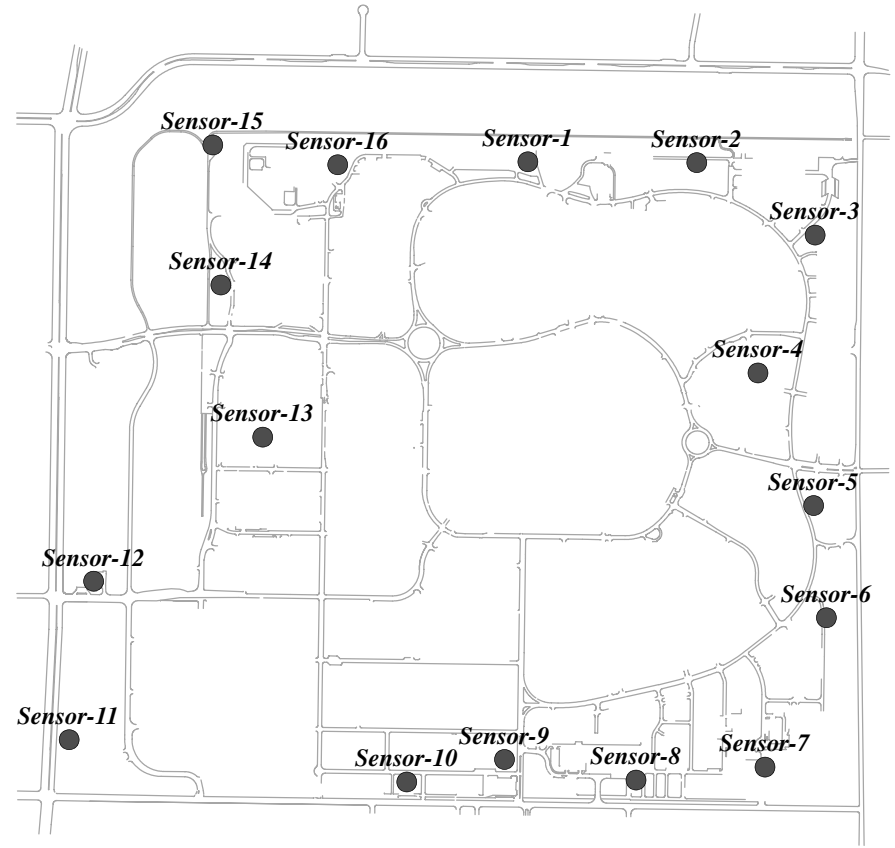

Figure 1. LLNL Site Map

\section{All Sensor Readings}

Tabular data for each sensor in the network is provided in the "All Sensor Readings" link. The data consists of the sensor's compass location, sensor identification, sensor readings, current sample interval and the time of the last reading (or sensor status, i.e., "offline", if not online).

\section{Emergency Response Page}

This page allows emergency responders to get a quick estimate of the 15-minute downwind plume that would be associated with a dispersion of radioactive material. The plume plot is calculated using average wind speed, average direction, and the average standard deviation of the wind direction, during the previous 15 minute sample interval from the LLNL meteorological tower. By default, this page assumes a static condition with a release point corresponding to the lab center, but for an actual consequence assessment, emergency responders enter the location of the release or an off-site location and the script plots a plume as appropriate. Figure 2 represents a "plume-sensor" interaction display example of this capability. It illustrates a source term of "off-site" origin with a plume passing through several sensor sites. The plume is represented by a centerline of average wind direction \pm a width parameter of the average directional standard deviation for the measurement period. The plume sector has a radial equivalent distance equal to the product of the average wind speed and sample period, plotted in km units. This is used as a leading edge plotted as a sector arc to determine sensor contact time. Color is used for plume definition in the program and not reproduced in this article.

The plume plot can be on-site or off-site depending on the radiological dispersion incident. With respect to a terrorist "dirty bomb" released at the perimeter, the plume passage event would be plotted for the current meteorological conditions indicating an on-site direction of travel as shown in Figure 2. Sensor contact is based on proximity to the source term and the prevailing conditions.

In this example, emergency responders would note that the succession of sensors contacted would be S-13, S-14, S-15, and S-16.

The Emergency Response Plot and the Simulation Plot both provide the following information:

- Source term origin

- Plume centerline

- 15-minute downwind equivalent radial distance

- Average wind speed (meters/second)

- Average direction from (azimuth degrees)

- Plot generation time-stamp

Additionally, the Simulation Plot provides:

- Sensor contact time

- Modeling reference coordinates

- Corresponding interval data

Note: (1) By convention, meteorology data is maintained using Pacific Standard Time (PST) throughout the year.

(2) This plot uses the LLNL local northing \& easting coordinate system

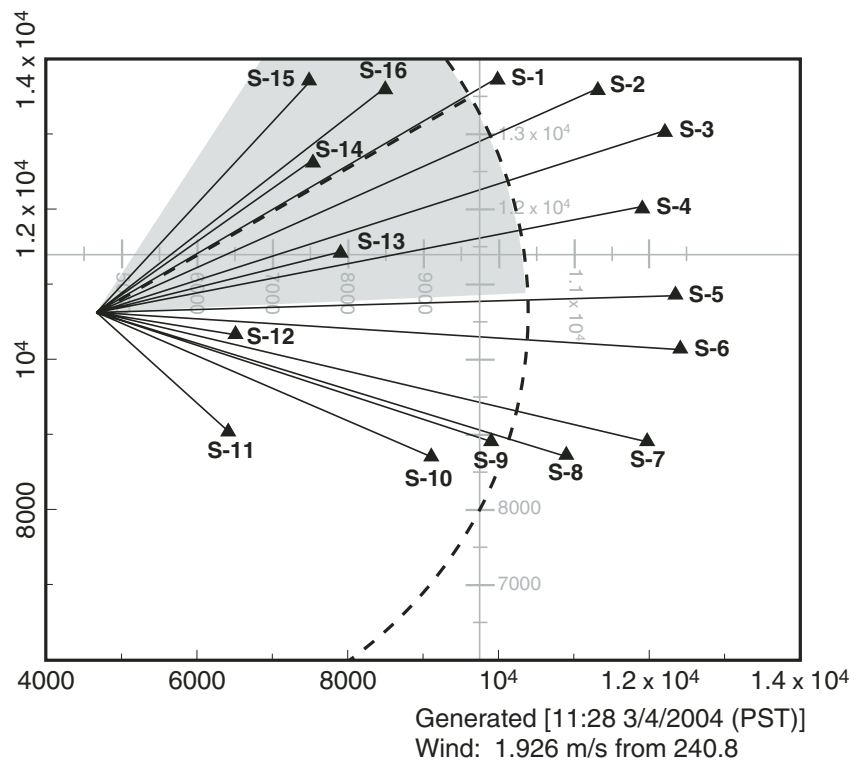

Figure 2. Emergency Response Plot

\section{E. Simulation}

The simulation page was created to take advantage of the secure intranet interface for emergency response exercises. The simulation link provides real-time or simulated data with real-time meteorological parameters as shown in the Emergency Response Plot of Figure 2. Often scenarios are planned to simulate an emergency conditions and the use of mock data can provide a measure of realism for personnel during an emergency exercise. Depicted in Figure 3, this intranet page example provides simulated real-time data which runs in the background from normal operations and does not interfere with the real site data collection process. This code is 
also used for data driven modeling to interface with air dispersion codes. The data provided indicates the sensor count rate and the geometrical reference parameters for use in the HOTSPOT [6] dispersion code.

\section{F. All plots: Last 4 Hours/All Locations}

This link provides the user with a plot of the data for each sensor on a per-minute basis with a 15 minute average overlay plotted for the previous 4 hour period as shown for one location in Figure 4. The utility of this link is in condition assessment using short-term trend analysis.

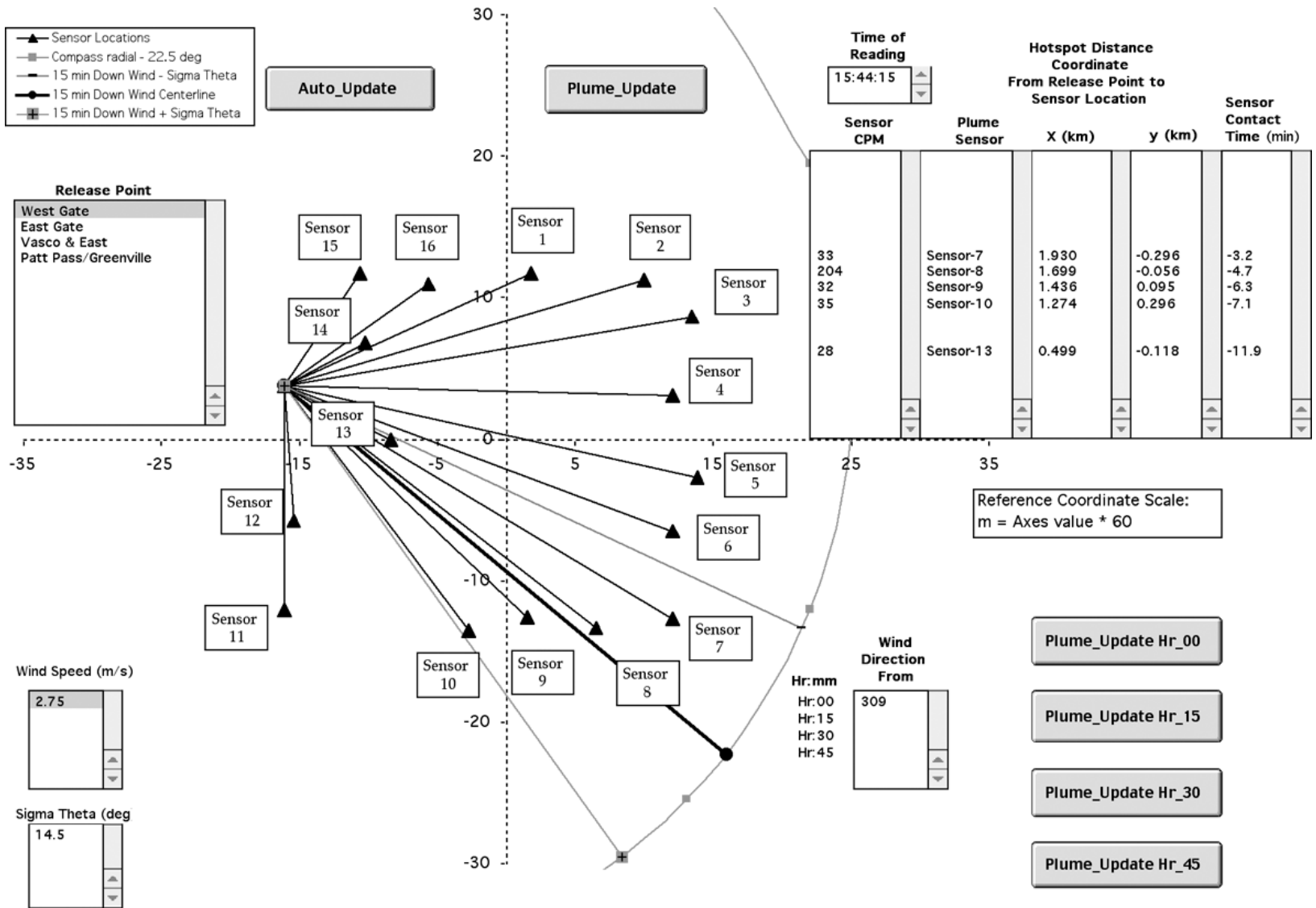

Figure 3. Simulation Plot 


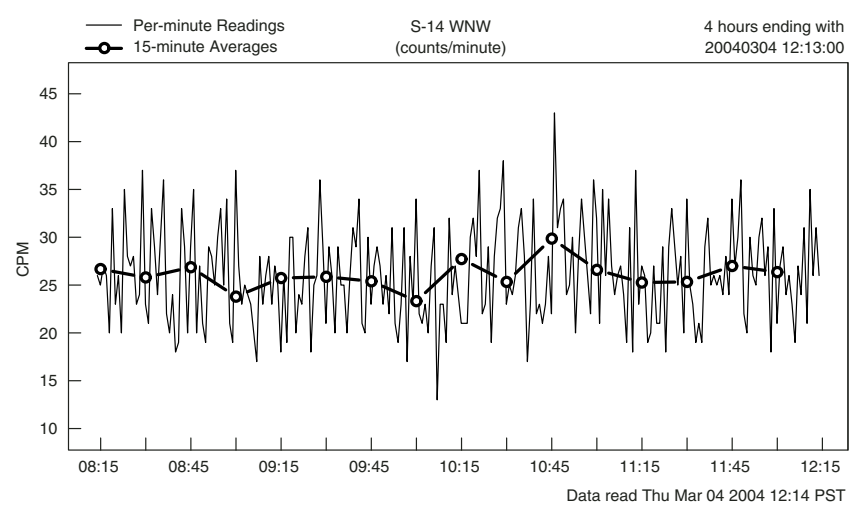

Figure 4. Count Rate Example for One Sensor Location

\section{G. Custom Plots}

Users have the option for examining data for any time period of history during which the system was online. This flexible utility is used to re-examine historical events and is easily accessed for presentation of data as needed. Figure 5 shows a sensor response to staged waste material.

In the event that this depiction were an actual plume passage event, adjacent sensors (S-7, S-9, and S-10) to the downwind centerline sensor (S-8) would also indicate elevated count rates and alarm as sensor contact was made. By comparing the data to the simulation plot in Figure 3, it is obvious that the adjacent sensors (within the defined plume) are maintaining background count rates. (All data presented in Figure 3 is simulated for the purpose of illustrating a comparison to the real data of Figure 5).

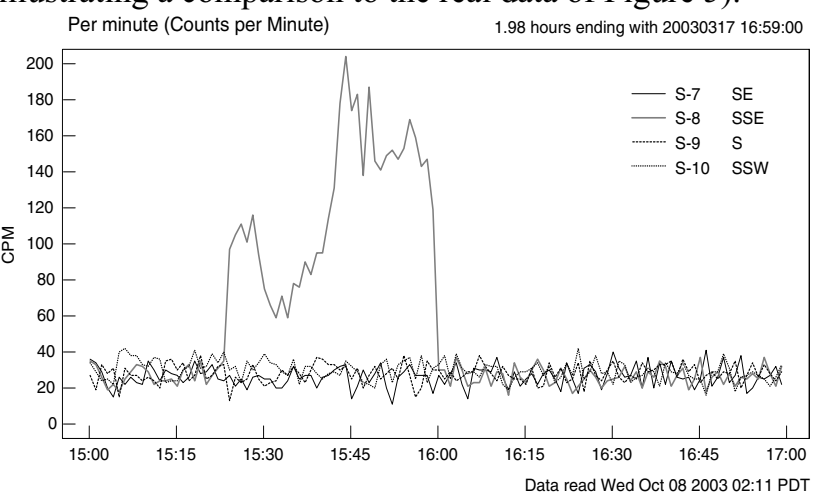

Figure 5. Custom Plot Example

\section{H. Action Level Status}

The action level status plot is one that emergency response personnel may utilize to guide field monitoring efforts. Computer based paging and email notices are provided by both the LabVIEW ${ }^{\mathrm{TM}}$ code running on the $\mathrm{CCC}$ computer and through $\mathrm{R}^{\mathrm{TM}}$ scripts monitoring the data and providing these plots. If a sensor is down or has been paralyzed by excessive activity this condition is easily discernable. The 4 action levels indicated in the status plot correspond to the calculated time that threshold dose parameter will be exceeded as given in Equation (1) above. An example of the Action Level Status plot is provided in Figure 6 .

\section{Generate Reports}

Users can request custom reports of per-minute data. They are allowed to select the sensors, start day/time and end day/time. The "Generate Reports" page also provides a link to download the tabular report to a spreadsheet.

\section{J. Daily Averages Four Locations / Plot}

The daily average link provides a glimpse of long-term average effects; these show, for example, seasonal changes regarding the effects of cosmic flux and radon emanations.

\section{K. LLNL Weather Data}

Additional information may be obtained from the LLNL meteorology internet site. This link provides the latest 15 minute update of current conditions from LLNL's tower.

\section{DATA INTEGRITY AND SECURITY}

\section{A. Data Integrity}

Data integrity of the RTRAM system is accomplished primarily through redundancy, monitoring, and the use of non-editable text. RTRAM data is stored in a number of separate locations, which must be in agreement which precludes the data from being compromised. The previously discussed alarm monitoring further ensures data integrity, alerting administrators to unexpected readings.

\section{B. Data Security}

Many precautions have been taken to ensure the security of the RTRAM intranet site. All servers associated with the RTRAM system reside within the protected computer network at LLNL. This network restricts access to computers within the protected network. RTRAM system access requires a programmatic sponsor with special provisions, as well as administrative and computer security program approval. Such access is closely monitored and controlled. Each individual host and intranet site in the RTRAM system is further protected with password controls and other measures.

\section{SOFTWARE INFRASTRUCTURE}

\section{A. Perl}

Perl is the open source programming language used for general RTRAM software development. Perl is a powerful programming language that is particularly useful at unifying programs and processes. Perl has a very active user community that contributes language extensions back into the public domain. Perl was used to develop the listener, monitoring scripts, and intranet. Perl was also used to provide interfaces to $R, \mathrm{MySQL}_{\circledast}$, and UNIX system utilities.

\section{B. $R$ Computer Language [7]}

$R$ is another flexible and powerful open-source programming language specialized for data analysis and graphics. $R$ is available for all of the computing platforms used in the project. The intranet file server runs Sun Microsystems $^{\mathrm{TM}}$ hardware with the Solaris ${ }^{\mathrm{TM}}$ operating 
system. Ad hoc data analysis takes place on Apple ${ }^{\circledR}$ computers using the MacOS $\mathrm{X}$ operating system. $R$ is also available for Linux and Windows ${ }^{\circledR}$ operating systems. $R$ has object-oriented capabilities, making it very easy to use any customized plotting or analysis functions that are developed.

\section{Hours to reach threshold dose (2 mrem) at present rate}

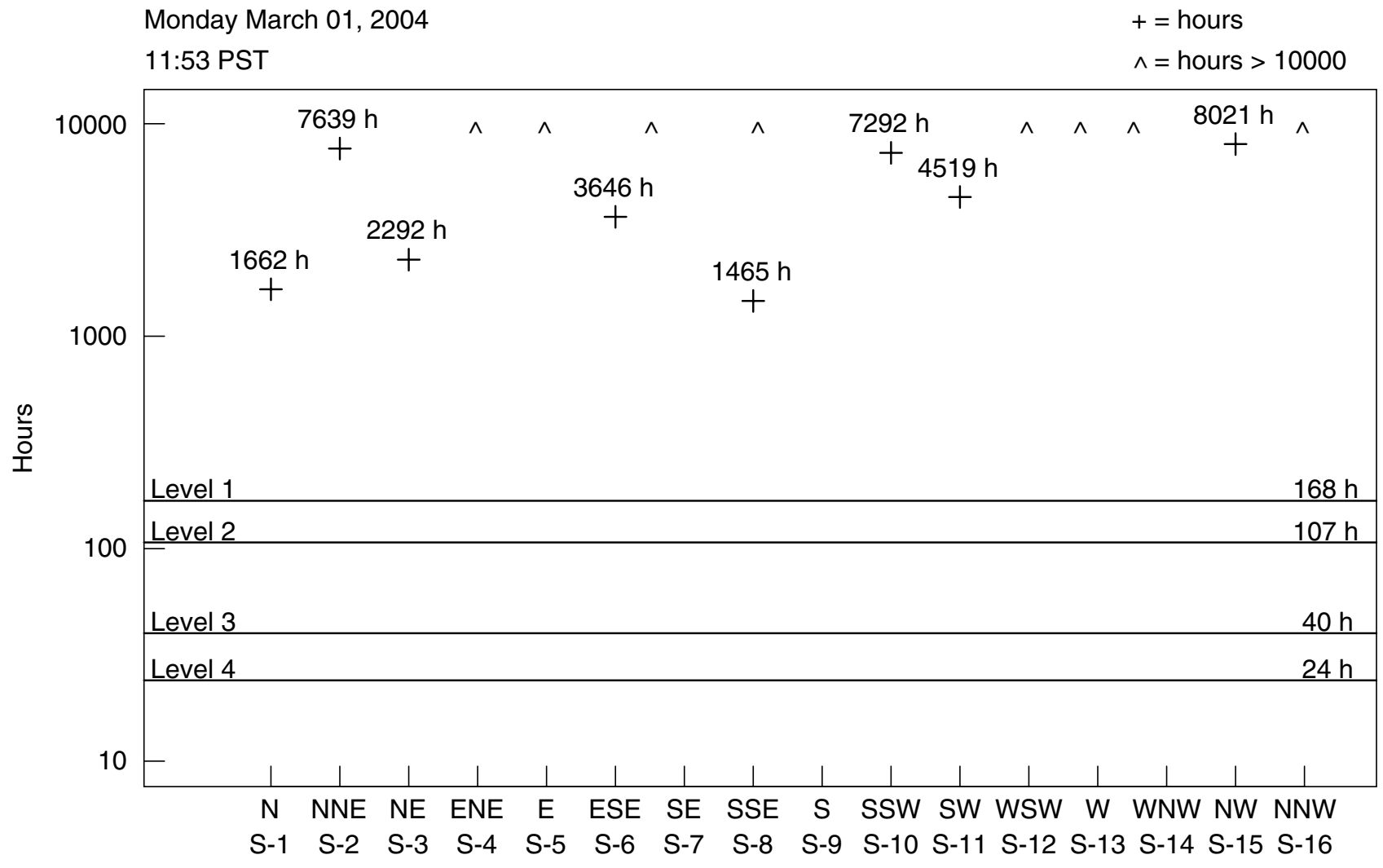

Figure 6. Action Level Status Plot

\section{C. $M y S Q L_{\circledast}$}

Although plain text files are convenient and easy to use, they are not conducive to storing "meta-data" information, such as information that might explain unusual measurements. For this reason, data is also stored in a relational database system. $\mathrm{MySQL}_{\circledast}$, another open-source software package, was selected because it has a relatively low administrative overhead.

\section{DATA ANALYSIS AND GRAPHICS}

We developed data analysis and graphical software routines using $R$ to meet the following needs:

- Prompt notification of unusually high activity levels

- Convenient routine review of recent activity levels

- Ad hoc review of activity levels (current, recent, or distant past)

- Examination of trends at different time scales (15 minute, hourly, or daily averages)

- Comparison of locations with each other
- Prompt detection of problems (interruptions in data collection, erroneous data)

As activity levels are measured, they are time-stamped; the times are always reported using an 8 hour offset from coordinated universal time (UTC) which correspond to (Pacific Standard Time). This eliminates any need to adjust for changes to and from daylight savings time during data collection and makes it directly compatible with LLNL meteorological data format. However, it is more convenient to display data using current local time. We felt this would be especially important during an unusual incident or emergency, so that individuals responding to the incident would not have to mentally translate times as they viewed graphics. $R$ was selected also because its date and time functions correctly handled this issue.

The software design for graphics and data analysis is modular. Modules fall into three basic categories: (1) data input, (2) data selection, and (3) data review. Data input consists of functions that retrieve data from storage. $R$ scripts run nightly to read all new data acquired since the 
previous night, and store it in $R$ 's internal format. Daily, hourly, and 15-minute averages are calculated at this time and stored along with the per-minute data. The data input functions may also be run manually at any time to examine selected data, without interfering with the regular daily data collection. Data selection consists of functions that let the user select which data to review by location and date range. Data review consists of functions to graph data in various ways, and check for special conditions such as unusually high activity levels or lapses in data collection.

Many of the data review functions are placed in scripts that are run at regular intervals, so that problems do not remain undetected. These scripts email summary reports to RTRAM staff. The script that monitors for action levels runs continuously. Special entries have been placed in the computer's startup scripts so that the monitoring script is automatically started whenever the computer is re-booted. The monitoring script is automatically checked hourly, and if it is not running it is restarted automatically.

Some of the $R$ scripts that run at regular intervals deliver plots to the intranet file server where users may view them. These include plots of the last four hours of measurements at every location, updated every five minutes; cumulative estimated dose updated daily; and daily averages for the last 90 days, updated daily.

\section{FUTURE RESEARCH}

\section{A. Portable sensors}

Low-power portable sensors with robust characteristics for extreme environmental conditions and communication via secure radio frequency link would be of significant value. Although there have been many advances recently in portable sensor technology, many have concentrated efforts in the properties of the unit and not included vital communication system components such as Global Positioning Systems, (GPS) and integrated smart communication systems.

Fire crews are often the primary first responders. The added value of on-scene command information during conditions of a radiological plume passage event would provide the crews with updated information as it is occurring and any other vital information that is best provided in a graphical content. Layers of graphical information provide this kind of data and the wireless technology need only be added to present configurable systems.

\section{CONCLUSION}

There are several difficulties in quickly identifying a potential radiological incident. The ability to identify radioactive material from a stand-off position and interdict a threat is possible but requires the strategic placement of sensors in a way that authorities may respond from multiple directions and inhibit movement of the material.

We have shown our ability to install and maintain a simple and reliable sensor network that extends over a 1 square mile area that has an immediate incident response mechanism. This leads us to consider the challenges associated with larger integrated network sensor systems and their use as a deterrent to accidental exposures and terrorist related threats to human life. Sensor systems of the future, whether radiological, chemical, or biological, should be capable not only of effective detection but also integrated communication of "sensed" information. With this they can become part of a strategy for interdiction where possible, or ad hoc consequence management to limit exposures to employees or to the general public.

\section{ACKNOWLEDGEMENT}

The authors would like to thank the management of the Environmental Protection Department for their funding support and former Department Head Harry L. Galles, for his initial support of the project. The authors would like to further acknowledge the effort of project team members Bert Heffner, Environmental Protection Department Community Relations; Paris Althouse Terrestrial \& Atmospheric Monitoring \& Modeling Group; Darrell Lager, Intranet Server Administration for the Environmental Restoration Division. The following supporting personnel made a significant contribution regarding installation and are acknowledged for their outstanding expertise that helped make this project a success: Gary Bear, and Duke Ramsey, Technical Support Group; and Electronic Technician's Pat Lewis, Electronics Engineering - Defense Sciences Engineering Division and Remy Carlis, Chemistry and Chemical Engineering Division; Plant Engineering Electrical Technician Edward Serrato, and Sheet Metal Technician Gil Serrato.

\section{REFERENCES}

[1] J.W. Healy, "Radioactive Cloud Dose Calculations," in Atmospheric Science and Power Production, Darryl Randerson, Editor. Technical Information Center, Office of Scientific and Technical Information, United States Department of Energy; DOE/TIC - 27601; 1984, pp. 685-745.

[2] G. Knoll, Radiation Detection and Measurement, Third Ed., New York, John Wiley and Sons Inc., 2000, pp. 201-217.

[3] G. Friedlander, J.W. Kennedy, E.S. Macias, J.M. Miller, "Nuclear and Radiochemistry," $3^{\text {rd }}$ Edition, John Wiley and Sons, Inc., 1981, pp. 251-252.

[4] E.A. Bemis Jr., "Survey Instruments and Pocket Dosimeters," in Radiation Dosimetry, G. J. Hine and G.L. Brownell, Editors. Academic Press Inc., 1956, pp. 472-474.

[5] W.D. Ehmann and D.E. Vance, "Radiochemistry and Nuclear Methods of Analysis," John Wiley and Sons Inc., 1991, pp. 218-219.

[6] S. Homann, "HOTSPOT Health Physics Codes for the PC," UCRLMA-106315, Lawrence Livermore National Laboratory, 1994.

[7] R Development Core Team, "R: A language and environment for statistical computing," R Foundation for Statistical, Computing, Vienna, Austria, 2003, ISBN 3-900051-00-3, URL http://www.Rproject.org. 


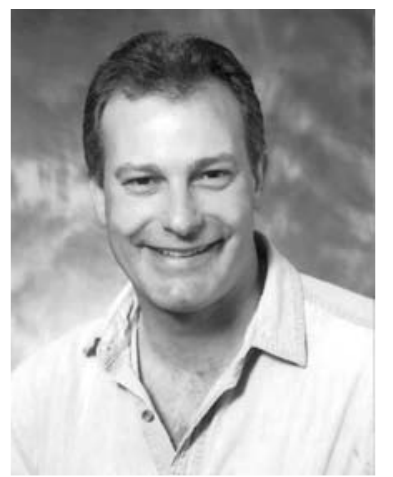

Nicholas A. Bertoldo received his M.S. degree in Radiological Health Physics from San Jose State University in 1998. Currently an LLNL Environmental Scientist in the Terrestrial \& Atmospheric Monitoring \& Modeling Group, Operations and Regulatory Affairs Division of the Environmental Protection Department. Presently serves as the Project Leader for the Real Time Monitoring Network. Nicholas is a Plenary Member of the Health Physics Society.

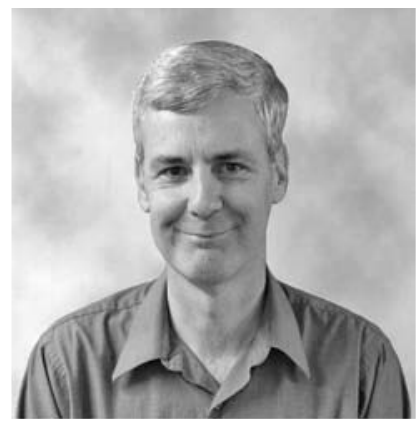

Steven Hunter received the BS degree in electrical engineering from The University of California, Berkeley in 1977 an the MS degree in electrical engineering from Case Western Reserve University in Cleveland Ohio in 1981.

$\mathrm{He}$ has been with Lawrence Livermore National Laboratory since 1981 where he provides instrumentation and low power embedded system support to a wide range of programs. He is a Senior Member of the IEEE.

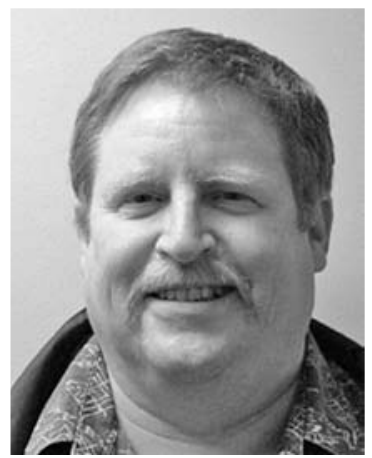

Ronald Fertig received his A.A. degree in Electronics Technology in 1979 from Butte Community College, Oroville, CA.

$\mathrm{He}$ has been with Lawrence Livermore National Laboratory since 1979. He currently is assigned to the Software Development and Control System Integration Group where he specializes in LabVIEW ${ }^{\mathrm{TM}}$ programming, providing fast, short-term support in instrumentation and control system development for a wide variety of projects at LLNL.

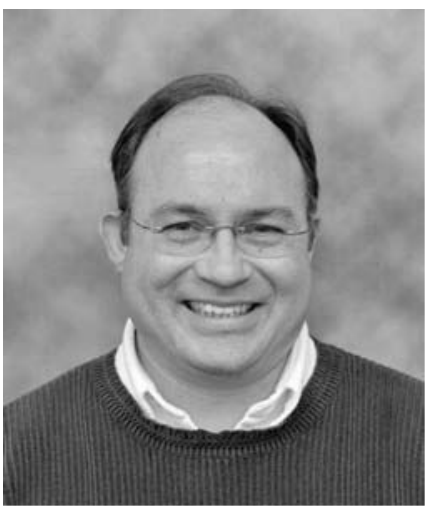

received his BS degree in Computer Science, Abilene Christian University, 1981, and MS in Computer Science, University of California, Davis, 1983. Gary is a computer scientist at Lawrence Livermore National Laboratory, where he has worked since 1981. In his current assignment he supports a wide variety of projects for the Environmental Protection Department, with an emphasis on intranet-based applications and application interfaces. He also serves as a group leader in the Computer Applications and Research Department. His past assignments at LLNL have been with Biomedical Research, Mechanical Engineering and Electronics Engineering, where he worked in the fields of computer graphics, solid modeling, product definition standards, mesh generation and visualization. Gary is a member of the Association for Computing Machinery, and a former vice-chair of the IEEE CS Technical Committee on Computer Graphics.

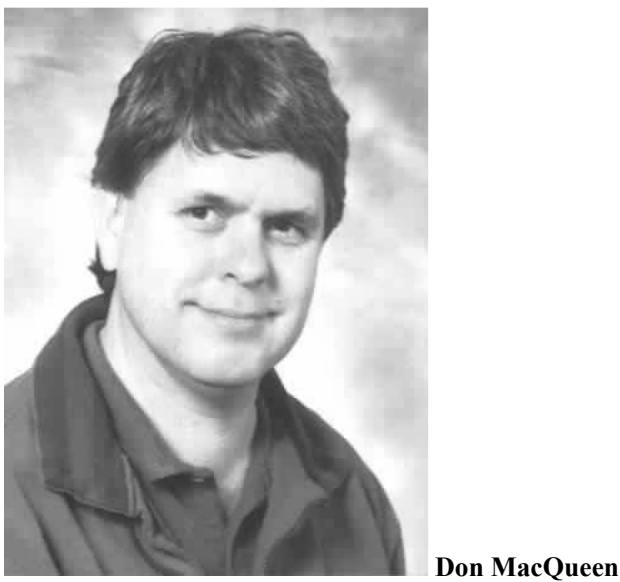

received a M.S. in statistics from California State University at Hayward in 1978. He joined LLNL in 1980. He currently works for the LLNL Environmental Protection Department as an environmental statistician. His activities for the department include data analysis and graphics, environmental database design, sampling design, and environmental quality control statistics. He is a member of the American Statistical Association and the International Environmetrics Society. 